The prevalence of otitis media with effusion is highest where social conditions are poor, ${ }^{+}$and children of non-manual workers have significantly better hearing than do those of manual workers. ${ }^{5}$ Cigarette smoking is commoner in those from the poorer socioeconomic classes but it is unlikely to be a risk factor for otitis media effusion, although it may have an association.

We thank Messrs G C Fox, $M$ Hardingham, and J M Robinson for allowing us to study their patients.
1 Maw AR. Otitis media with effusion (glue ear). In: Kerr AG, Groves J, Evans NG, eds. Scott-Brown's otolaryngology. 5th ed. Vol 6. London: Butterworth, 1987:159-76

2 Hinton AE. Surgery for otitis media with effusion in children and it relationship to parental smoking. $\mathcal{L}$ Laryngol Otol 1989;103:559-61.

3 Strachan DP, Jarvis MJ, Feyerabend C. Passive smoking, salivary cotinine concentrations, and middle ear effusion in 7 year old children. $B M \mathcal{J}$ 1989;298:1549-52.

4 Robinson GC, Anderson DO, Moghadam HK, Cambon KG, Murray AB. A survey of hearing loss in Vancouver school children. Part 1. Methodology and prevalence. Can Med Assoc F 1967;97:1199-207.

5 Richardson K, Peckam CS, Goldstein H. Hearing levels of children tested at 7 and 11 years. A national study. Br $\mathcal{F}$ Audiol 1976;10:117-23.

(Accepted 24 fune 1991)

\section{Menarche and reproduction after treatment for African Burkitt's lymphoma}

\author{
Janet E Neequaye, Julianne Byrne, \\ Paul H Levine
}

\begin{abstract}
Burkitt's Tumor Project, Department of Child Health, University of Ghana Medical School, Accra, Ghana Janet E Neequaye, MRCP, associate professor of child health
\end{abstract}

\section{Epidemiology and} Biostatistics Program, National Cancer Institute, National Institutes of Health, Bethesda, Maryland, USA

Julianne Byrne, PHD, senior staff fellow

Paul H Levine, MD, senior investigator

\section{Correspondence to:}

Dr J E Byrne, EPN 400,

National Cancer Institute,

NIH, Bethesda, MD 20892,

USA.

BMF 1991;303:1033 as children.

\section{Patients, methods, and results}

African Burkitt's lymphoma is a rapidly progressing cancer that responds quickly to cyclophosphamide. ${ }^{1}$ Since 1966 the Burkitt's Tumor Project in Accra has treated children with Burkitt's lymphoma chiefly by cyclophosphamide. A troublesome side effect after cyclophosphamide, however, is sterility. ${ }^{2}$ We sought to determine how chemotherapy might influence fertility in adults who had been treated for Burkitt's lymphoma

Between 1984 and 1988 we attempted to interview and draw blood from every person treated at the University of Ghana Medical School for Burkitt's lymphoma between 1966 and 1988 who was at least 16 in 1988 and had survived at least five years from date of diagnosis. Because of difficulty in tracing boys results are given for girls only. Survivors were diagnosed at an average age of 9 years (range 3-17). All except three were prepubertal at diagnosis. All children were treated with cyclophosphamide and some also with other drugs. Cyclophosphamide was given fortnightly in boluses of $1400 \mathrm{mg} / \mathrm{m}^{2}$ intravenously until remission, which was usually after three doses. The total dose ranged from $2.8 \mathrm{~g} / \mathrm{m}^{2}$ in two patients to roughly 9.0 $\mathrm{g} / \mathrm{m}^{2}$ in five $(90-300 \mathrm{mg} / \mathrm{kg})$

Blood was sampled at the time of interview and date of the last menstrual period noted. Serum follicle stimulating hormone and luteinising hormone concentrations were measured by double antibody radioimmunoassay using the second international reference preparation as standard.

Most former patients lived in small rural villages with no access to postal or telephone systems. After excluding male patients and those who could not be located we interviewed 24 female survivors (two by proxy) and 13 sisters or neighbours as controls.

At follow up no survivor was still having treatment. All but two of the women were in good general health. One was blind and another had a chronic foot ulcer due to sensory deficit accompanying paraplegia. Both problems resulted from the tumour.

Survivors were similar to controls in age at interview, years of schooling, and sexual and marital experiences (table). Survivors, however, reached menarche significantly later than controls (age $13.5 v 12.2$ years; $\mathrm{p}<0.05$ ). This could not be attributed to treatment during puberty as the average age at menarche among the 16 survivors treated before age 11 was $13 \cdot 3$ years.

Of the 22 women trying for children, 21 had had at least one pregnancy. One woman who was treated for three weeks at age 11 , reached the menarche at 16 , and was 24 at follow up reported irregular periods and infertility for seven years. Sixteen of 17 married survivors had at least one child. Blood from 13 women was tested for follicle stimulating hormone and luteinising hormone concentrations. In none of these women were values abnormal.

Reproductive experiences of female survivors of African Burkitt's lymphoma and controls

\begin{tabular}{lcc}
\hline & Survivors & Controls \\
\hline Total No studied & 24 & 13 \\
No(\%) with menstrual problems & $1(4)$ & 0 \\
No(\%) ever had sexual intercourse & $23(96)$ & $12(92)$ \\
No(\%) married & $17(71)$ & $12(92)$ \\
No(\%) married with children & $16 / 17(94)$ & $12 / 12(100)$ \\
Average age at first live birth (years) & $18 \cdot 6$ & $19 \cdot 5$ \\
Average age at menarche (years) & $13 \cdot 5$ & $12 \cdot 2^{\star}$ \\
Average age at marriage (years) & $18 \cdot 4$ & $18 \cdot 6$ \\
\hline
\end{tabular}

${ }^{\star} \mathrm{p}<0 \cdot 05(\iota$ test $)$

\section{Comment}

In this small study most female survivors of Burkitt's lymphoma seemed to be fertile. The single potentia problem noted was the delay in menarche by more than one year. So far as we know this is the first such repor after treatment with cyclophosphamide, which previously has been associated with dose dependen gonadal dysfunction. ${ }^{3}$ The doses received in our study were just below that range. ${ }^{3}$ To date the longest follow up of girls treated with cyclophosphamide (for the nephrotic syndrome) indicated normal fertility in 16 of 18 women in their mid-20s, but age at menarche was not studied."

Follow up studies of survivors of cancer treated with various agents found changes in timing of menarche, some recording an earlier age at menarche, others a later age. Reasons for this effect are unclear. We also do not know what implication this would have for the timing of menopause.

This study was supported by the National Cancer Institute, National Institutes of Health, Bethesda (contract No NO1-CP-51009). We acknowledge the staff of the Burkitt's Tumor Project, Accra, for their help and in particular Mrs Emelia Buadoo, who interviewed the subjects, often under difficult circumstances.

1 Burkitt DP. Long-term remissions following one and two-dose chemotherapy for African lymphoma. Cancer 1967;20:756-9.

2 Koyama H, Wada T, Nishizawa Y, Iwanaga T, Aoki Y, Terasawa T, et al Cyclophosphamide-induced ovarian failure and its therapeutic significance in patients with breast cancer. Cancer 1977;36:1401-9.

3 Rivkees SA, Crawford JD. The relationship of gonadal activity and chemo therapy-induced gonadal damage. FAMA 1988;259:2123-5.

4 Watson AR, Taylor J, Rance CP, Bain J. Gonadal function in women treated with cyclophosphamide for childhood nephrotic syndrome: a long-term follow-up study. Fertil Steril 1986;46:331-3.

5 Quigley C, Cowell C, Jimenez M, et al. Normal or early development of puberty despite gonadal damage in children treated for acute lymphoblastic leukemia. N Englf Med 1989;321:143-51.

(Accepted 29 May 1991) 